J. Lake Sci.(湖泊科学), 2016, 28(2): 295-302

DOI 10. 18307/2016. 0208

(c) 2016 by Journal of Lake Sciences

\title{
三峡澎溪河回水区高水位期间高阳平湖总磷模型”
}

\author{
赫 斌 ${ }^{1}$, 李 哲 ${ }^{2,3 * *}$, 冯 婧 ${ }^{1}$, 肖 艳 ${ }^{2,3}$, 郭劲松 2,3 \\ ( 1 : 重庆大学城市建设与环境工程学院, 重庆 400044) \\ (2: 中国科学院水库水环境重点实验室,重庆 400714) \\ (3: 中国科学院重庆绿色智能技术研究院,重庆 400714)
}

\begin{abstract}
摘 要: 三峡水库 “蓄清排浑” 的调度运行方式使得冬季高水位期间近岸消落带受淹. 消落带氮、磷等营养物受淹后向水 体中释放与积累对冬末初春的水华将可能具有重要贡献. 构建高水位时期澎溪河高阳平湖总磷收支模型,定量分析高水 位期间总磷的收支途径、累积量以及累积磷的主要来源。结果表明: 蓄水期,由于蓄水水位升高和顶托而导致大量磷积 累; 稳定期, 磷收支变幅较小, 总体趋于平缓; 水华期, 前期积累的磷被大量消耗, 形成水华. 淹没消落带磷释放是冬季高 水位时期高阳平湖总磷的主要来源, 蓄水期所淹没大量消落带所释放的磷为冬季末水华暴发提供条件. 研究结果为后续 定量分析磷形态的转化和分配奠定重要基础.
\end{abstract}

关键词: 三峡水库; 高水位时期; 澎溪河; 总磷收支模型; 消落带; 高阳平湖

\section{Total phosphorus model in Lake Gaoyang during the period of high water level in Pengxi River backwater zone, Three Gorges Reservoir}

\author{
HE Bin ${ }^{1}$, LI Zhe ${ }^{2,3 * *}$, FENG Jing ${ }^{1}$, XIAO Yan $^{2,3}$ \& GUO Jinsong ${ }^{2,3}$ \\ ( 1: Faculty of Urban Construction and Environmental Engineering, Chongqing University, Chongqing 400044, P.R.China) \\ (2: Key Laboratory of Water Environment Reservoir, Chinese Academy of Sciences, Chongqing 400714, P.R.China) \\ (3: Chongqing Institute of Green and Intelligent Technology, Chinese Academy of Sciences, Chongqing 400714, P.R.China)
}

\begin{abstract}
The mode of operation of storing clear and releasing muddy in Three Gorges Reservoir makes drawdown areas submerged alongshore during the period of high water level in winter. After drawdown areas are submerged, the accumulation and release of nutrients such as nitrogen and phosphorus may have an important contribution to the algae bloom at the end of winter. This article establishes a model of the total phosphorus, which analyzes the balance of payments and the cumulant of total phosphorus, as well as the main source of cumulative phosphorus during the period of high water level in Lake Gaoyang of Pengxi River. In impounding stage, the increasing water level led to a great amount of phosphorus accumulation. In stable stage, the total tends to be mild. In algae bloom stage, the accumulation of phosphorus is consumed heavily in early time, forming algae bloom. The release of phosphorus in submerged drawdown area is the main source of total phosphorus throughout the period in Lake Gaoyang. It provides conditions for the outbreak of algae bloom at the end of winter. The results have set a solid foundation for the conversion and distribution of phosphorus forms.
\end{abstract}

Keywords: Three Gorges Reservoir; high water level; Pengxi River; total phosphorus budget model; drawdown area; Lake Gaoyang

磷是影响内陆水体富营养化过程的关键生源要素. 为揭示天然水体中总磷 (TP) 的收支及其与富营养 化的关系, 1970s, 国际上开始关注于水体 TP 浓度收支关系计算以用来服务环境管理 ${ }^{[1]}$. 较早的 TP 模型是 Vollenweider 于 1975 年提出 ${ }^{[1-3]}$, 此后 Dillon 等对 Vollenweider 模型进行修正, 提出不同湖水 TP 浓度的数学

* 国家自然科学基金项目 $(51179125,51309220)$ 和中国科学院西部行动计划项目 (KZCX2-XB3-14)联合资助. 2015- 02-13 收稿;2015-05-12 收修改稿. 赫斌(1991 ), 男, 硕士研究生;E-mail : binhe85@163.com.

** 通信作者; E-mail : Lizhe@ cigit.ac.cn. 
模型 ${ }^{[4]}$. 但上述模型均未考虑底质与水体界面的磷交换过程 ${ }^{[5]}$. Welch 等 ${ }^{[6]}$ 进一步改进 Vollenweider 模型, 使其包括一个恒定的底质磷释放速率. 考虑到底质磷交换的动态性, Lorenzen 等 ${ }^{[7]}$ 构建底质-水相相互作用 的 TP 模型. 不仅如此, Steven ${ }^{[2]}$ 和 Kamp ${ }^{[8]}$ 对此逐步进行改进. 相比较于更为复杂的生态动力学模型, TP 收支模型结构简单, 所需的模型参数少, 容易建构并验证, 故在湖泊和水库富营养化分析中, 依然是常用且 强大的分析工具.

三峡成库后的支流富营养化与频发的水华现象近年来备受关注. 前期调查研究中普遍观点认为水库 氮、磷等营养物丰富而通常不易成为限制性因子, 但关于支流 TP 收支关系鲜见报道. 受 “蓄清排浑” 调度运 行的影响, 水库冬季蓄水进入枯季高水位状态, 伴随近岸消落带受淹、水库库容增加, 支流回水区将可能出 现显著的磷积累现象, 并可能对冬末初春水华产生显著贡献. 为揭示上述现象, 本文选择三峡典型支流澎 溪河回水区的高阳平湖段, 在 Vollenweider 的 TP 收支模型基础上, 建立枯季高水位时期高阳平湖 TP 收支模 型. 定量分析高水位期间 TP 的收支途径、累积量以及累积磷的主要来源, 为后续定量分析磷形态的转化和 分配奠定基础.

\section{1 材料与方法}

\section{1 研究区域与样品采集}

澎溪河地处四川盆地东部边缘, 流域面积 $5173 \mathrm{~km}^{2}$, 干流全长 $182.4 \mathrm{~km}$. 其下游回水区高阳平湖水域 ${ }^{[9]}$ (图 1), 经峡谷流人此处, 流速减缓, 具有类似湖泊的地貌环境及水文水力特征. 该水域在夏季低水位阶段 平均水深不足 $10 \mathrm{~m}$, 冬季高水位阶段平均水深将超过 $40 \mathrm{~m}$, 水域物理边界呈现显著的季节性交替特征. 为 开展对 TP 收支关系的计算, 本研究选择高阳平湖人口 $\left(31^{\circ} 6^{\prime} 12^{\prime \prime} \mathrm{N}, 108^{\circ} 39^{\prime} 12^{\prime \prime} \mathrm{E}\right.$; 简写为 “高阳 1”)、湖心 $\left(31^{\circ} 5^{\prime} 48^{\prime \prime} \mathrm{N}, 108^{\circ} 40^{\prime} 20^{\prime \prime} \mathrm{E}\right.$; 简写为 “高阳 2”), 出口 ( $31^{\circ} 4^{\prime} 60^{\prime \prime} \mathrm{N}, 108^{\circ} 40^{\prime} 14^{\prime \prime} \mathrm{E}$; 简写为 “高阳 3”) 为控制性断 面 (图 1). 于 2011 年 9 月至 2012 年 3 月一个完整的高水位运行阶段开展逐月跟踪观测.
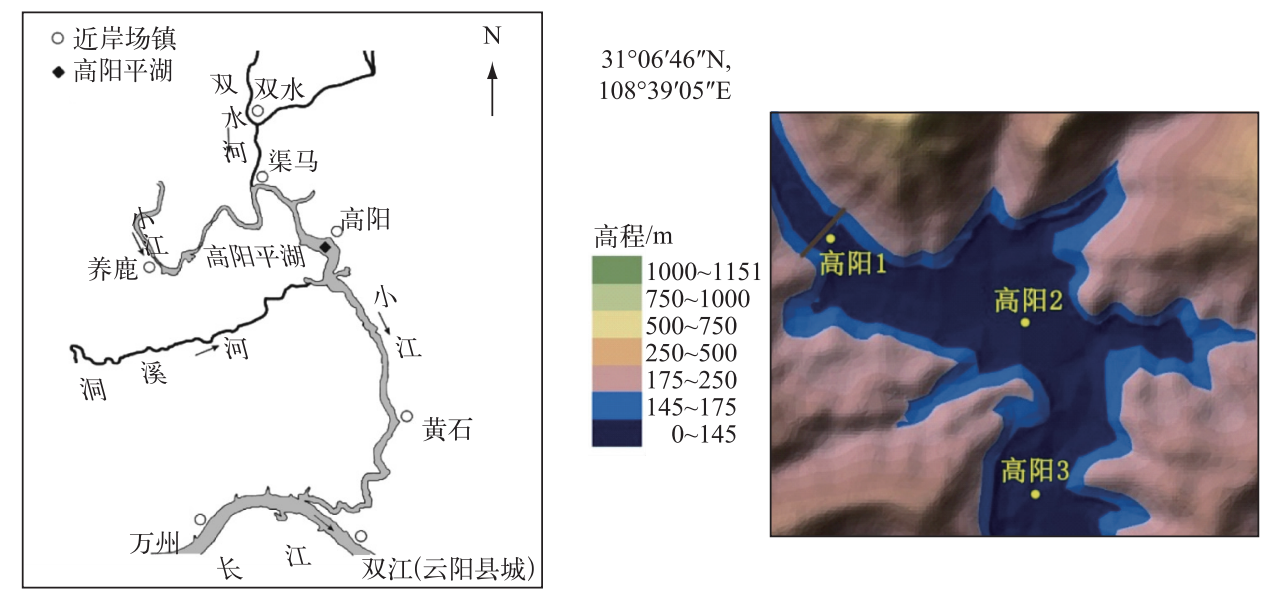

$31^{\circ} 04^{\prime} 50^{\prime \prime} \mathrm{N}$, $108^{\circ} 41^{\prime \prime} 27^{\prime \prime} \mathrm{E}$

图 1 澎溪河回水区云阳段及高阳平湖示意和采样点位置

Fig.1 Backwater area of the Pengxi River and sampling sites in Lake Gaoyang

消落带土壤采集在高阳平湖库湾平台附近进行, 于水面上大约 $0.2 、 5 、 10 、 20 \mathrm{~m}$ 处消落带斜坡面分梯度 采样. 使用柱状采样器 (采样管高 $55 \mathrm{~cm}$ 、内径 $10.5 \mathrm{~cm}$ ) 进行采样, 然后切取 $0 \sim 20 \mathrm{~cm}$ 的表层样品放于自封 袋中冷藏保存带回实验室, 用于分析消落带土壤的活性磷; 在高阳平湖库湾平台附近水面靠近河床处使用 柱状采样器采集底泥样品, 采集后将样品放于自封袋中冷藏保存带回实验室用于测定底泥的活性磷.土壤 监测时间为 2011 年 9 月至 2012 年 3 月,采样频次为 1 次/月,采样时间控制在采样当天 $9: 30-16: 30$.

根据高阳平湖冬季高水位时期水文与水生态特征, 将冬季高水位时期划分为 3 个阶段: 1 ) 蓄水期 (9 月 中旬一 10 月下旬) : 汛末蓄水, 在持续 $40 \mathrm{~d}$ 左右的时间内, 水位不断上升, 高阳平湖库容不断增加. 2) 稳定期 
(11 月上旬一次年 1 月下旬) : 三峡水位在 $170 \sim 175 \mathrm{~m}$ 附 近维持高水位运行, 高阳平湖库容和淹没消落带面积达 到最大, 具有类似深水湖泊的水文水力特征 . 3 ) 水华期 ( 2 月上旬一 3 月下旬) : 处于高水位运行末期, 水库开始 下泄放水, 冬季末期气温逐渐回暖, 易于形成水华. 研究 期间三峡水库坝前水位如图 2 所示.

\section{2 测定指标}

测定指标包括: 水温、 $\mathrm{TP} 、$ 消落带活性磷 $\left(p s_{1}\right)$ 、永久 淹没区活性磷 $\left(p s_{2}\right)$, 活性磷计算方法为: 活性磷 = 总磷 无机磷+颗粒物表面的吸附磷+铝磷+铁磷 ${ }^{[11]}$. 土壤总磷 和无机磷采用磷钼蓝比色法 ${ }^{[11]}$; 吸附磷、铝磷、铁磷采用 SMT 连续浸提法 ${ }^{[12]}$. 水质化学测试指标分析方法参照 《水和废水监测分析方法》进行 ${ }^{[11]}$, 土壤化学测试指标分

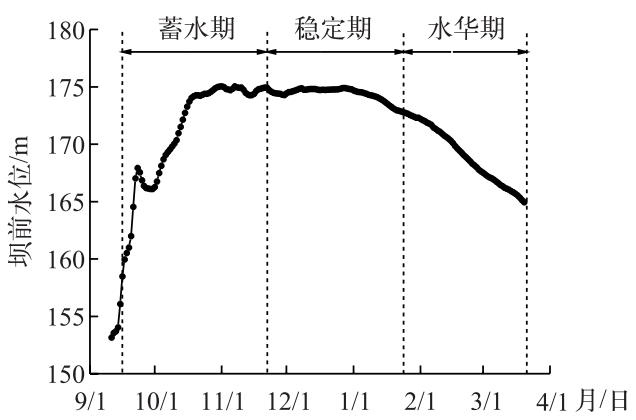

图 2 研究期间三峡水库坝前水位变化

Fig. 2 Variation of water level in the Three Gorges Reservoir during the research 析方法参照《土壤农业化学分析方法》进行 ${ }^{[12]}$.

\section{3 数据来源与分析方法}

本文所有数据均录人 Excel 软件或 Origin 软件进行统计分析, 采用变异系数 $C V$ 值表征数据变化幅度. 模型计算中所需的水位数据来自于中国长江三峡集团网站; 日流量数据根据开县温泉水文站 (占 $24 \%$ 控制 流域面积) 流量实测数据进行换算; 气候气象数据直接来自于研究团队设置在高阳平湖库湾的气象站. 不 同水位下的高阳平湖库容、水域面积与消落带实际面积, 以 $175 \mathrm{~m}$ 以下 $1: 2000 \mathrm{DEM}$ 为基础, 采用 ArcGIS 直 接提取.

\section{2 高水位期间高阳平湖 TP 模型的建构}

\section{1 时空边界与模型基本假设}

本研究集中于揭示冬季蓄水后高水位时期的 TP 收支关系,故研究的时间边界为 9 月末 (汛末蓄水开 始) 至次年 3 月 (第一场明显降雨来临之前) 整个高水位运行期间, 空间边界为高阳平湖高阳 1 、高阳 3 控制 断面内的 $175 \mathrm{~m}$ 高程以下的水域、永久淹没区与消落带. 模型具有以下假设:

1) 因研究期间位于冬季,高阳平湖水体不分层且枯水期未出现异重流等改变水质空间分布的现象 ${ }^{[13]}$, 故水域内不存在水平和垂直空间位置差异, 假设变量与参数均为空间均质性 ${ }^{[13-15]}$. 不考虑因水动力学条件 改变而产生的各种生态要素时空迁移特征, 即所构建的 TP 模型为零维 ${ }^{[16]}$.

2) 因云阳县高阳污水处理厂排污口位于高阳 3 断面下游 $500 \mathrm{~m}$ 处,故模型中暂不考虑高阳镇点源输人 的影响.

3) 因研究期间为冬季枯水季节,期间降水量仅为全年的 10\% 20\%, 且相比较于高阳平湖水域面积 (水 位 $175 \mathrm{~m}$ 以下为 $92 \mathrm{~km}^{2}$ ), 高阳 1 高阳 3 断面间控制流域面积很小 (约为 $95 \mathrm{~km}^{2}$ ), 故模型中忽略面源污染 导致的 TP 输人.

4) 高阳平湖位于澎溪河回水区中段,距澎溪河长江汇人口约 $20 \mathrm{~km}$. 根据“十一五”水专项子课题《水位 调节坝水质水量调度控藻技术研究》(2008ZX07104-005-005) 模拟结果, 因三峡水库运行导致的倒灌并不影 响到本研究所在的高阳平湖,故不考虑高阳 3 断面可能存在的倒灌问题.

5) 在模型设计中以 $1 \mathrm{~d}$ 为一个稳态单位, 将高水位时期简单的看成是多个稳态状态下的连续过程. 假 设每一个稳态条件下 (即 $1 \mathrm{~d}$ 内) 磷释放率和沉降速率保持不变, 水体体积不变, 单位时间流人水体流量 $=$ 流 出水体流量.

6) 模型为 TP 模型, 不考虑食物网中的捕食关系 (如鱼类对藻类捕食) 导致的水体 TP 浓度变化. 因研 究期间为冬季高水位时期,水生生物活性较低, 且水深较大, 故在底泥磷释放中, 不考虑底栖动物的贡献.

7) 因为冬季水流平稳, 流体扰动较小, 沉积物仅考虑上层 $0.2 \mathrm{~m}, 0.2 \mathrm{~m}$ 深度以下的沉积物磷假定不参 与系统代谢. 


\section{2 TP 模型结构与基本方程}

根据上述假设,视高阳平湖为一个完全混合反应器 (CSTR), 采用 Steven ${ }^{[2]}$ 在 Vollenweider 模型 ${ }^{[1-3]}$ 基础 上针对底质与水体相互作用的修改版为基础, 其 TP 收支中的源汇项与反应项分别为:

1) 输人项: 高阳 1 断面自上游 TP 输人, 高阳平湖陆源 (点源、非点源) TP 输人 (本模型中假设为 0 )、水 位升高消落带磷释放、永久淹没区底泥磷释放; 2) 输出项: 高阳 3 断面向下游 $\mathrm{TP}$ 输出; 3 ) 反应项: 高水位期 间磷的沉积 (颗粒态磷的沉降), 永久淹没区底泥同水体的交换.

其中, 模型认为消落带为新受淹土壤, 与永久淹没区底泥已经相对稳定的水-底泥磷交换存在显著区别. 故模型中将消落带受淹后同水体磷交换的系数和永久淹没区内底泥同水体的磷交换系数分别处理. 据此, 模型基本方程为:

$$
V \frac{\mathrm{d} p}{\mathrm{~d} t}=W-Q \cdot p-v_{\mathrm{s}} \cdot V \cdot p+v_{\mathrm{r} 1} \cdot A_{\text {消落带 }} \cdot p s_{1}+v_{\mathrm{r} 2} \cdot A_{\text {永久流没区 }} \cdot p s_{2}
$$

式中, $V$ 为湖水的容积 $\left(\mathrm{m}^{3}\right)$, 随水位变化而变化; $p$ 为湖水总磷浓度 $\left(\mathrm{g} / \mathrm{m}^{3}\right) ; t$ 为时间 $(\mathrm{d}) ; W$ 为高阳平湖中的 磷负荷量 $(\mathrm{g} / \mathrm{d}) ; Q$ 为流量 $\left(\mathrm{m}^{3} / \mathrm{d}\right) ; v_{\mathrm{s}}$ 为总磷沉降速率 $(1 / \mathrm{d}) ; v_{\mathrm{r} 1}$ 和 $v_{\mathrm{r} 2}$ 分别为从消落带和永久淹没区到水体

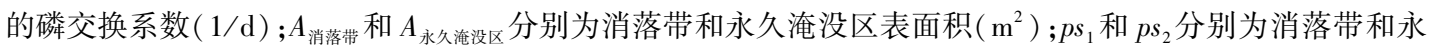
久淹没区土壤活性磷浓度 $\left(\mathrm{g} / \mathrm{m}^{2}\right)$.

其中, 从消落带和永久淹没区到水体的磷交换系数 $v_{\mathrm{r} 1}$ 和 $v_{\mathrm{r} 2}$, 主要受温度影响, 根据 Vant't Hoff 方程, 表 述为:

$$
\begin{aligned}
& v_{\mathrm{r} 1}=K m_{2} \cdot \theta m_{2}^{T-20} \\
& v_{\mathrm{r} 2}=K m_{3} \cdot \theta m_{3}^{T-20}
\end{aligned}
$$

式中, $K m_{2}$ 和 $K m_{3}$ 分别为 $20^{\circ} \mathrm{C}$ 时消落带磷和永久淹没区磷的矿化率 $(1 / \mathrm{d}), \theta m_{2}$ 和 $\theta m_{3}$ 分别为其温度系数.

根据上述分析,对于总磷模型而言,各磷库的速率和通量计算公式见表 1.

表 1 总磷模型速率 $(\mathrm{g} / \mathrm{d})$ 和通量 $\left(\mathrm{g} /\left(\mathrm{d} \cdot \mathrm{m}^{3}\right)\right)$ 的计算公式

Tab. 1 Formulas of phosphorus fluxes and rates of conversion of TP model

\begin{tabular}{lcc}
\hline 磷库 & 速率计算公式 & 通量计算公式 \\
\hline $\mathrm{TP}$ 累积 & $W-Q \cdot p-v_{\mathrm{s}} \cdot V p+v_{\mathrm{r} 1} \cdot A_{\text {消落带 }} \cdot p s_{1}+v_{\mathrm{r} 2} \cdot A_{\text {永久淹没区 }} \cdot p s_{2}$ & $\left(W-Q \cdot p+v_{\mathrm{r} 1} \cdot A_{\text {消落带 }} \cdot p s_{1}+v_{\mathrm{r} 2} \cdot A_{\text {永久淹没区 }} \cdot p s_{2}\right) / V-v_{\mathrm{s}} \cdot p$ \\
$\mathrm{TP}$ 上游输人 & $Q \cdot p$ 人 & $Q \cdot p$ 人 \\
$\mathrm{TP}$ 下游输出 & $Q \cdot p$ & $Q \cdot p / V$ \\
$\mathrm{TP}$ 沉降 & $v_{\mathrm{s}} \cdot V_{p}$ & $v_{\mathrm{s}} \cdot p$ \\
消落带水土界面磷交换 & $v_{\mathrm{r} 1} \cdot A_{\text {消落带 }} \cdot p s_{1}$ & $v_{\mathrm{r} 2} \cdot A_{\text {消落带 }} \cdot p s_{1} / V$ \\
永久淹没区水土界面磷 & $v_{\mathrm{r} 2} \cdot A_{\text {永久淹没区 }} \cdot p s_{2}$ & $v_{\mathrm{r} 2} \cdot A_{\text {永久淹没区 }} \cdot p s_{2} / V$ \\
\hline
\end{tabular}

初始条件下, 根据相关文献 ${ }^{[17-19]}$ 和前期研究结果, 对模型参数设置初始估值, 见表 2.

表 2 总磷模型参数估值

Tab. 2 Parameters for TP model simulation

\begin{tabular}{lcclc}
\hline 参数 & 符号 & 单位 & 取值 & 方法 \\
\hline TP 沉降速率 & $v_{\mathrm{s}}$ & $1 / \mathrm{d}$ & 0.05 & 文献[17] \\
$20^{\circ} \mathrm{C}$ 时消落带磷矿化率 & $K m_{2}$ & $1 / \mathrm{d}$ & 0.05 & 本实验测定 \\
$20^{\circ} \mathrm{C}$ 时永久淹没区磷矿化率 & $K m_{3}$ & $1 / \mathrm{d}$ & 0.0025 & 文献[18-19] \\
消落带磷矿化温度系数 & $\theta m_{2}$ & - & 1.15 & 文献[19] \\
永久淹没区磷矿化温度系数 & $\theta \mathrm{m}_{3}$ & - & 1.15 & 文献[19] \\
\hline
\end{tabular}

\section{3 TP 模型求解与验证}

因采用稳态假设, 故在确定每天相关因变量的基础上, 在 Excel 表格基础上直接进行算术计算, 获得模 型预测与模拟结果. 模型校样采用状态变量校对误差 $(Y)$ 、平均状态变量校对误差 $(R)$ 和最大状态变量校 
对误差 $(A)$ 这 3 个校准指标来定量表示. 若 3 个指标的值都比较小, 则此模型具有预测价值 ${ }^{[20-21]}$. 其公式分 别为:

$$
\begin{gathered}
Y(\%)=\left\{\left[\sum\left(Y_{\mathrm{c}}-Y_{\mathrm{m}}\right)^{2}\right]^{1 / 2} / n\right\} / \overline{Y_{\mathrm{m}}} \times 100 \% \\
R(\%)=\left(\overline{Y_{c}}-\overline{Y_{\mathrm{m}}}\right) / \overline{Y_{\mathrm{m}}} \times 100 \% \\
A(\%)=\left(Y_{\mathrm{c}, \text { max }}-Y_{\mathrm{m}, \text { max }}\right) / Y_{\mathrm{m}, \max } \times 100 \%
\end{gathered}
$$

式中, $Y_{\mathrm{c}} 、 \overline{Y_{\mathrm{c}}}$ 和 $Y_{\mathrm{c}, \mathrm{max}}$ 分别为校验期模拟值、平均模拟值和最高 模拟值, $Y_{\mathrm{m}}, \overline{Y_{\mathrm{m}}}$ 和 $Y_{\mathrm{m}, \text { max }}$ 分别为校验期实测值、平均实测值和最 高实测值.

模型校样结果 (图 3) 表明, 模型能较好地描述高阳平湖高 水位时期 TP 浓度的动态变化, 模拟值与实测值两者的变动趋 势基本一致. 模型中 $\mathrm{TP}$ 浓度校验指标 $Y 、 R$ 和 $A$ 值分别为 $2.078 \% 、 5.749 \%$ 和 $-6.753 \%$, 可以看出其误差在 $10 \%$ 以内, 在 仅提供少量测量数据的情况下,上述差异被认为可接受.

\section{3 结果与分析}

\section{1 高水位不同阶段各磷库总磷的转化速率}

在高阳平湖 TP 模型基础上, 对高阳平湖磷累积、磷沉降 以及磷交换等关键过程进行计算,结果见表 4.

在蓄水初期, TP 累积速率和消落带水土界面磷交换速率

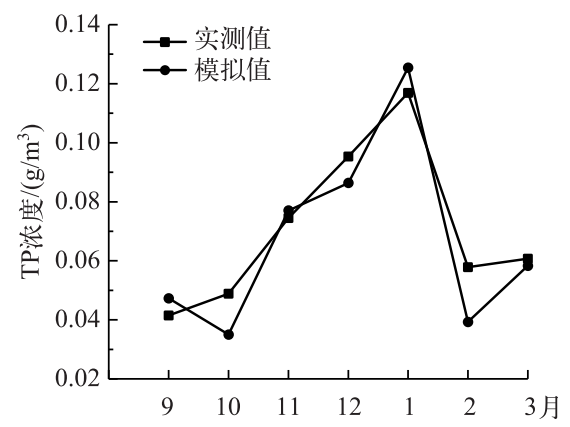

图 3 研究期间高阳平湖高水位 时期 TP 浓度模拟值与实测值

Fig.3 Simulation and measurement of TP concentration in Lake Gaoyang during high water level stage 都存在不同幅度的上升趋势, 并在此时达到整个高水位时期的 最大值, 随后在蓄水中后期开始存在不同幅度的下降,总体而言都为正值; 永久淹没区水土界面磷交换速率 在蓄水期逐渐下降; 而 TP 沉降速率呈逐渐上升趋势(图 4).

表 4 研究期间高阳平湖高水位时期各磷库 TP 的转化速率*

Tab. 4 Rates of conversion between the different phosphorus pools in Lake Gaoyang during high water level stage

\begin{tabular}{lccccc}
\hline 项目 & 参数 & 整个高水位时期 & 蓄水期 & 稳定期 & 水华期 \\
\hline TP 累积速率 & 均值 $/\left(\times 10^{5} \mathrm{~g} / \mathrm{d}\right)$ & $16.96 \pm 12.11$ & $35.33 \pm 5.81$ & $13.28 \pm 2.98$ & $6.08 \pm 2.59$ \\
& 范围 $/\left(\times 10^{5} \mathrm{~g} / \mathrm{d}\right)$ & $0.09 \sim 48.33$ & $23.53 \sim 48.33$ & $6.59 \sim 22.08$ & $0.09 \sim 10.16$ \\
& 变异系数 $C V$ & 71.39 & 16.44 & 22.48 & 42.56 \\
$\mathrm{TP}$ 沉降速率 & 均值 $/\left(\times 10^{5} \mathrm{~g} / \mathrm{d}\right)$ & $5.22 \pm 2.74$ & $2.74 \pm 1.06$ & $7.93 \pm 1.46$ & $3.52 \pm 1.40$ \\
& 范围 $/\left(\times 10^{5} \mathrm{~g} / \mathrm{d}\right)$ & $1.66 \sim 10.53$ & $1.66 \sim 5.47$ & $5.64 \sim 10.53$ & $2.36 \sim 7.36$ \\
& 变异系数 $C V$ & 52.46 & 38.57 & 18.37 & 39.75 \\
消落带水土界面磷交换速率 & 均值 $/\left(\times 10^{5} \mathrm{~g} / \mathrm{d}\right)$ & $14.70 \pm 9.61$ & $29.13 \pm 5.00$ & $11.59 \pm 2.79$ & $5.53 \pm 1.03$ \\
& 范围 $/\left(\times 10^{5} \mathrm{~g} / \mathrm{d}\right)$ & $3.87 \sim 40.57$ & $19.43 \sim 40.57$ & $7.60 \sim 20.18$ & $3.87 \sim 7.47$ \\
& 变异系数 $C V$ & 65.37 & 17.13 & 24.09 & 18.69 \\
永久淹没区水土界面磷交换速率 & 均值 $/\left(\times 10^{5} \mathrm{~g} / \mathrm{d}\right)$ & $3.26 \pm 2.50$ & $6.83 \pm 1.99$ & $2.50 \pm 0.55$ & $0.96 \pm 0.29$ \\
& 范围 $/\left(\times 10^{5} \mathrm{~g} / \mathrm{d}\right)$ & $0.29 \sim 10.80$ & $3.99 \sim 10.80$ & $1.36 \sim 3.89$ & $0.29 \sim 1.34$ \\
& 变异系数 $\mathrm{CV}$ & 76.74 & 29.14 & 21.83 & 30.63 \\
\hline
\end{tabular}

*变异系数无单位.

稳定期, TP 累积速率及消落带和永久淹没区水土界面磷交换速率在整个时期大体表现较平稳. 其中 $\mathrm{TP}$ 累积速率在前期出现几次短暂的陡降; 消落带水土界面磷交换速率在中期出现短暂的上升; 永久淹没区 水土界面磷交换速率略有上升后继续平缓下降; TP 沉降速率在该时期逐渐上升,并在稳定期末期达到整个 高水位时期的峰值. 


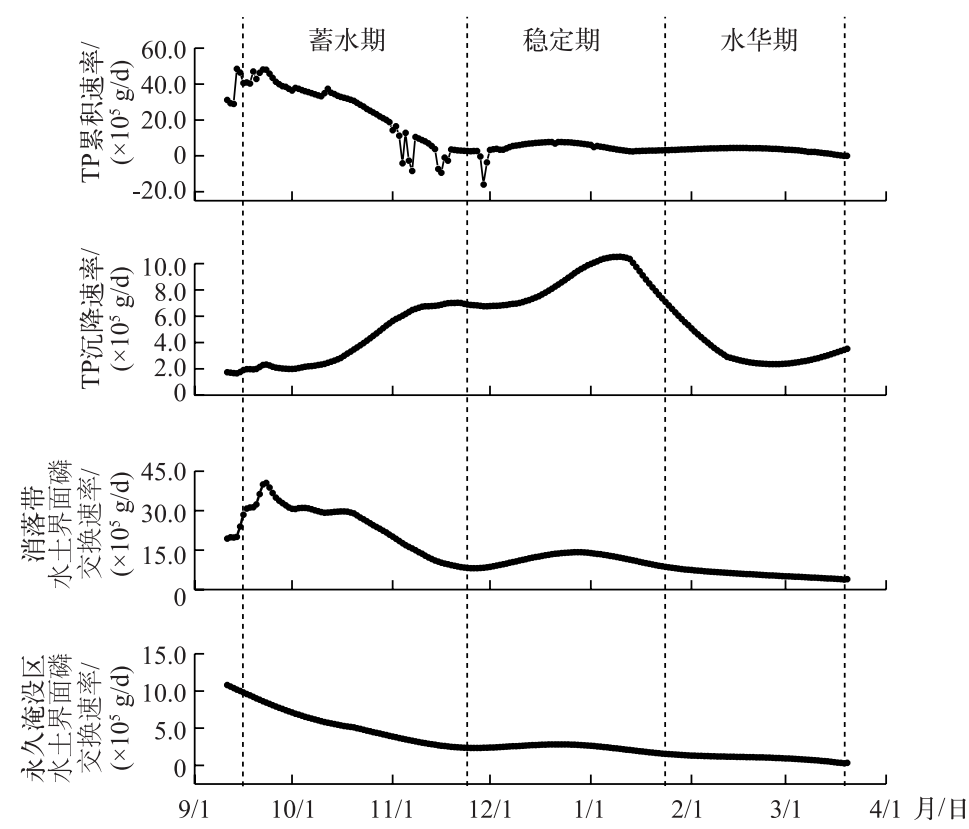

图 4 研究期间高阳平湖高水位时期各磷库 TP 的转化速率

Fig.4 Rates of conversion between different phosphorus pools in Lake Gaoyang during high water level stage

水华期, TP 累积速率在该时期大体表现平稳并在末期逐渐下降; 消落带和永久淹没区水土界面磷交换 速率在该时期呈逐渐下降趋势, 并在水华期末期达到整个高水位时期的最低值, 但总体都为正值; TP 沉降 速率在水华期呈先下降后小幅上升趋势.

\section{2 高水位期间不同阶段各磷库 TP 通量}

高阳平湖高水位期间不同阶段各磷库 TP 通量(图 5) 表明, TP 累积通量与消落带和永久淹没区水土界 面磷交换通量具有相同的变化趋势, 在蓄水期达到最大值, 随着时间增加而逐渐降低, 在水华期达到最低, 即在蓄水期出现磷量的累积, 而在高水位中期开始随即出现累积磷量下降; 而 TP 沉降通量在 3 个时期都表 现出较平稳的状态, 仅在稳定期略高一些.

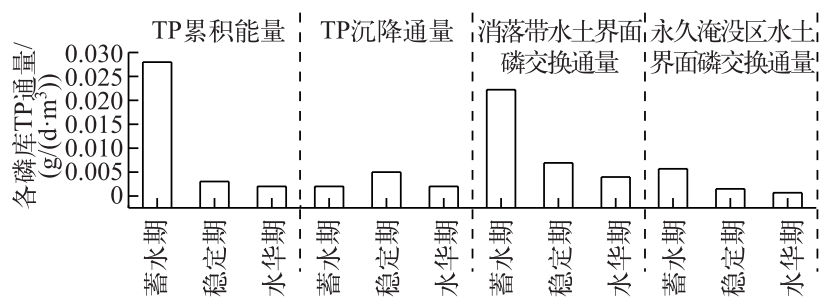

图 5 研究期间高阳平湖高水位不同阶段各磷库 TP 通量

Fig.5 Phosphorus fluxes of different phosphorus pools in Lake Gaoyang

\section{4 讨论}

蓄水期,持续不断的蓄水导致大量 TP 随流水带人高阳平湖. 水位增高也使得淹没消落带面积不断增 多, 被淹消落带在物理和生化过程作用下逐渐向上覆水中释放碳、氮、磷等物质 ${ }^{[22-23]}$, 因而在蓄水初期 TP 累 积速率、消落带水土界面磷交换速率不断增加. 研究发现, 在蓄水期消落带和永久淹没区土壤磷释放动力 学过程是个由快转慢的过程 ${ }^{[24-27]}$, 即在蓄水初期具有较大磷释放速率而到了蓄水中后期磷释放速率逐渐减 
缓, 磷释放量逐渐达到最大值, 动力学趋向于平衡. 因此在蓄水中后期, TP 累积速率和消落带水土界面磷交 换速率开始下降; 永久淹没区随着淹没时间增长, 水土界面磷交换速率在此期间呈现下降趋势; 在整个蓄水 期, 随着水位逐渐逼近最高水位, 径流量逐渐减少和水位雍升的交替作用使得此时高阳平湖流速逐渐减缓, 水体滞留时间延长, 加之降雨量的明显减少, 水体中悬浮颗粒物逐渐下降, 因而在整个蓄水期 TP 沉降速率 逐渐增大. 蓄水期间, 静水压力增加亦可能影响消落带和底泥的磷释放, 并可能影响高阳平湖磷达到释放一 沉降动态平衡的时间. 但本模型中假设底泥和消落带的磷释放并不受静水压力影响. 后续研究将对此进行 进一步修正完善.

稳定期, 蓄水达到最大库容, 水库进人冬季枯水季节, 上游来水较少, 高阳平湖水体接近静止状态, 动力 条件近似于深水湖泊, 因而 TP 沉降速率在蓄水期的基础上持续增大 ${ }^{[28]}$; 在经历蓄水期的浸泡后, 消落带和 永久淹没区水土界面磷释放速率已达到动态平衡; TP 累积速率在此时变幅较小, 总体趋于平缓并且都表现 为正值.

水华期,受到水位逐渐降低和水体扰动的影响,使得 TP 沉降速率受到干扰,在该时期呈下降趋势; 水位 的下降也使得淹没消落带面积减少, 消落带水土界面磷交换速率也逐渐减小, 并到达整个高水位时期的最 低值; 永久淹没区受到水位变化的影响较小, 水土界面磷交换速率达到动态平衡, 略有下降; 出湖水量的增 加和内源释放的减少使得 TP 累积速率呈现稳步降低的趋势.

综上所述,在高水位蓄水期, 由于蓄水水位升高和顶托而导致大量磷积累. 因此利用 TP 模型对 20112012 年整个高水位时期 TP 收支途径和累积量进行模拟. 在冬季高水位时期, 高阳平湖水中 TP 主要通过上 游 TP 输人、消落带和永久淹没区磷释放这 3 种途径来累积, 通过下游输出和水体总磷沉降这 2 种途径来支 出 (图 6). 对于收人途径来说, 永久淹没区磷释放通量占输人总通量的 $13.48 \%$, 消落带磷释放通量高于上 游 TP 输人通量, 占输人总通量的 $57.37 \%$, 是冬季高水位时期高阳平湖 TP 的主要来源. 这说明由于蓄水水 位升高和顶托所淹没的消落带在一定程度上成为库区重要的磷源, 并可能对冬末初春水华形成具有重要贡 献. 对于支出途径来说, 下游 TP 输出通量略高于 TP 沉降通量, 成为 TP 支出的首要途径, 占 TP 总支出通量 的 $63.41 \%$.

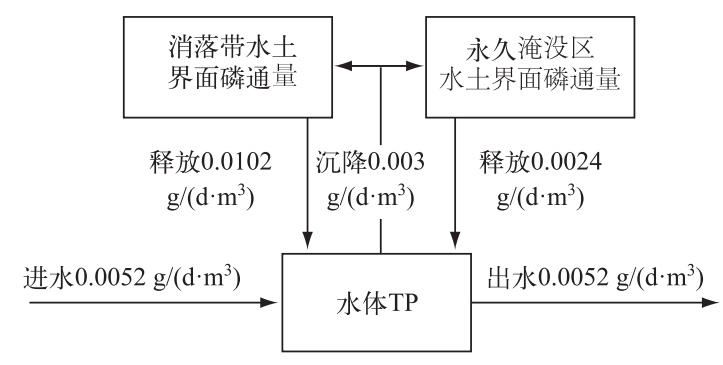

图 6 研究期间高阳平湖高水位时期 TP 累积通量示意

Fig.6 Fluxes of TP accumulation in Lake Gaoyang during high water level stage

\section{5 结论}

在高阳平湖高水位蓄水期、稳定期和水华期这 3 个阶段中各磷库 TP 通量各不相同, 冬季高水位时期的 外源性 TP 输人、输出基本相当. 蓄水期, 由于蓄水水位升高和顶托而导致磷大量累积; 稳定期, 磷收支变幅 较小, 总体趋于平缓; 水华期, 前期积累的磷被大量消耗, 形成水华. 淹没消落带是冬季高水位时期高阳平 湖 TP 的主要来源 (占输人总通量的 $57.30 \%$ ), 由于蓄水水位升高和顶托所淹没大量消落带所释放的磷为冬 季末水华暴发提供条件.

\section{6 参考文献}

[ 1 ] 顾丁锡, 舒金华. 湖水总磷浓度的数学模拟. 海洋与湖沼, 1988, 19(5): 447-455. 
[ 2 ] Steven CC. Long-term phenomenological model of phosphorus and oxygen for stratified lake. Water Research, 1991, 25(6) : 707-715.

[ 3 ] 金相灿, 屠清瑛. 湖泊富营养化调查规范: 第 2 版. 北京: 中国环境科学出版社, 1990.

[ 4 ] Canale PR, Seo D. Performance reliability and uncertainty of total phosphorus models for lakes II. Stochastic analyses. Water Research, 1996, 30(1): 95-102.

[ 5 ] 全为民, 严力蛟. 湖泊富营养化模型研究进展. 生物多样性, 2001, 9(2): 168-175.

[ 6 ] Welch EB, Spyridakis DE, Shuster JI. Declining lake sediments phosphorus release and oxygen diversion. Journal of Water Pollution Control Federation, 1986, 58(1): 92-96.

[ 7 ] Lorenzen CT. Primary production in the sea. Cambridge: Blackwell Scientific Publication, 1976: 173-185.

[ 8 ] Kamp NL. Modeling the temporal variation in sediment phosphorus fractions. In: Golterman HL ed. Interactions between sediments and fresh water. Germany: Springer-Verlag, 1978: 277-285.

[ 9 ] 冯 婧, 李 哲, 间 涁. 三峡水库不同运行阶段澎溪河典型优势藻原位生长速率. 湖泊科学, 2014, 26(2): 235-242. DOI 10. 18307/2014. 0210.

[10］李 哲, 方 芳, 郭劲松. 三峡小江回水区段 2007 年春季水华与营养盐特征. 湖泊科学, 2009, 21 (1): 3644. DOI 10. 18307/2009. 0105.

［11］国家环境保护总局《水和废水监测分析方法》编委会. 水和废水监测分析方法: 第 4 版. 北京: 中国环境科学出 版社, 2002: 243-285.

[12］鲁如坤. 土壤农业化学分析方法. 北京: 中国农业科技出版社, 2000.

[13] Li Z, Zhang Z, Xiao Y et al. Spatio-temporal variations of carbon dioxide and its gross emission regulated by artificial operation in a typical hydropower reservoir in China. Environmental Monitoring and Assessment, 2014, 186( 5) : 3023-3039.

[14] 李 哲, 王 胜, 郭劲松. 三峡水库 $156 \mathrm{~m}$ 蓄水前后澎溪河回水区藻类多样性变化特征. 湖泊科学, 2012,24 (2) : 227-231. DOI 10.18307/2012.0209.

[15] 蒋 滔, 郭劲松, 李 哲. 三峡水库不同运行状态下支流澎溪河水-气界面温室气体通量特征初探. 环境科学, $2012,33(5)$ : 1463-1470.

[16] 方 芳, 李 哲, 田 光. 三峡小江回水区磷素赋存形态季节变化特征及其来源分析. 环境科学, 2009, 30 (12) : 3488-3493.

[17] 李耀初, 李适宇, 周劲风. 肇庆星湖水质模型研究. 重庆环境科学, 1999, 21(2) : 38-41.

[18］阮景荣, 蔡庆华, 刘建康. 武汉东湖的磷-浮游植物动态模型. 水生生物学报, 1988, 12(4): 289-307.

[19］周 宏. 杭州西湖引水后生态系统中磷循环模型. 生态学报, 1998, 18(6): 648-653.

[20] Jørgensen SE, Bendoricchio G. Fundamentals of ecological modelling . Access Online via Elsevier, 2001.

[21] Pei H, Ma J. Study on the algal dynamic model for West Lake, Hangzhou. Ecological Modelling, 2002, 148(1) : 67-77.

[22] 袁 辉, 王里奥, 胡 刚等. 三峡库区消落带受淹土壤氮和磷释放的模拟实验. 环境科学研究, 2008, 21 (1): 103-106.

[23] 袁 辉, 黄 川, 崔志强等. 三峡库区消落带与水环境响应关系预测. 重庆大学学报: 自然科学版, 2007, 30 (9) : 134-138.

[24] 王里奥, 黄 川, 詹艳慧等. 三峡库区消落带淹水一落干过程土壤磷吸附一解吸及释放研究. 长江流域资源与 环境, 2006, 15(5): 593-597.

[25] 金丹越, 王圣瑞, 步青云. 长江中下游浅水湖泊沉积物磷释放动力学. 生态环境, 2007, 16(3) : 725-729.

[26] Kim LH, Choi E, Stenstrom MK. Sediment characteristics, phosphorus types and phosphorus release rates between river and lake sediments. Chemosphere, 2003, 50(1): 53-61.

[27] McDowell R, Sharpley A. Phosphorus solubility and release kinetics as a function of soil test P concentration. Geoderma, 2003, $112(1)$ : 143-154.

[28］李 哲. 三峡水库运行初期小江回水区藻类生境变化与群落演替特征研究 [学位论文]. 重庆: 重庆大学, 2009. 